\title{
Asymptomatic Coronary Artery Disease in a Pregnant Patient
}

\author{
A Case Report and Review of Literature
}

\author{
J. Stewart Collins, Eduardo Bossone, Kim A. Eagle, Rajendra H. Mehta'
}

\begin{abstract}
Background: Acute myocardial infarction during pregnancy has been reported and has been shown to be associated with poor maternal and fetal outcomes. However, the vast majority of these patients do not have previously recognized ischemic heart disease. Pregnancy and delivery pose significant cardiac stress and risk to the mother and fetus. However, it is unknown how available therapies can be utilized in the pregnant patient with identified ischemic heart disease to minimize these risks.

Case Report: We present a 39-year-old asymptomatic diabetic female with a positive stress echocardiogram at 16 weeks of pregnancy who remained asymptomatic throughout pregnancy with medical management and went on to have a nor-
\end{abstract}

mal vaginal delivery in the process suffering a small non-ST elevation myocardial infarction with pulmonary edema following delivery due to volume overload. She ultimately underwent cardiac catheterization and successful four-vessel CABG 1 month after her delivery.

Conclusion: We present this patient to suggest a successful strategy of managing a patient with non-revascularized asymptomatic coronary artery disease during pregnancy. In addition to reviewing the appropriate medical therapy during pregnancy, we discuss the data on revascularization procedures as well as recommendations for delivery and stress testing for such patients.

Key Words: Pregnancy · Coronary artery disease · Ischemic heart disease - Management · Revascularization • Coronary artery bypass graft

Herz 2002;27:548-54

DOI $10.1007 / \mathrm{s} 00059-002-2402-7$

\section{Asymptomatische koronare Herzkrankheit bei einer Schwangeren. Fallbericht und Literaturübersicht}

Hintergrund: Tritt ein akuter Herzinfarkt während der Schwangerschaft auf, ist die Prognose für Mutter und Kind ungünstig. Die Mehrheit dieser Patientinnen hat in der Vorgeschichte keine koronare Herzerkrankung. Die Schwangerschaft und Geburt bedeuten eine starke kardiale Belastung und ein Risiko für Mutter und Kind. Unbekannt ist jedoch bisher, welche Therapien schwangeren Patientinnen angeboten werden können, die eine ischämische Herzerkrankung haben, um das Risiko zu mindern.

Fallbericht: Es wird über eine 39-jährige asymptomatische diabetische Patientin berichtet, die ein positives Belastungsechokardiogramm 16 Wochen nach Schwangerschaftsbeginn aufwies und die während der Schwangerschaft unter Therapie asymptomatisch blieb. Während der Geburt entwickelte die Patientin einen kleinen ST-Hebungs-Infarkt mit Lungenödem durch die erfolgte Volumenbelastung. Eine sofort durchgeführte Herzkatheteruntersuchung zeigte eine Mehrgefäßerkrankung, die operativ 1 Monat nach der Geburt versorgt wurde.

Zusammenfassung: Anhand dieses Fallbeispiels wird aufgezeigt, wie Patienten mit ischämischer koronarer Herzerkrankung während der Schwangerschaft betreut werden. Die mögliche medikamentöse Therapie während der Schwangerschaft wird dargestellt. Die Möglichkeit der Revaskularisation wird diskutiert und Empfehlungen zur Geburt und zu Stresstests bei solchen Patienten gegeben.

Schlüsselwörter: Schwangerschaft · Geburt · Koronare Herzerkrankung · Therapie · Revaskularisation · ACVB · Stresstests $\cdot$ Echokardiographie $\cdot$ Herzinfarkt

\footnotetext{
'Division of Cardiology, Department of Internal Medicine, University of Michigan, Ann Arbor, USA.
}

Presented in part at the Annual Meeting of The Michigan Chapter of The American College of Cardiology, October 2001. 


\section{Introduction}

There are several reports of acute myocardial infarction (AMI) complicating pregnancy that have been associated with poor maternal and fetal outcomes [1,2]. Most of these myocardial infarctions have been a result of coronary dissection rather than ruptured plaque or increased stress of pregnancy in patients with stable coronary artery disease. There is only one case report of successful pregnancy following myocardial ischemia in a patient with newly diagnosed coronary artery disease [3]. Given the current trend toward childbearing later in life, we anticipate that this scenario will be seen more frequently especially in those patients with multiple risk factors. However, currently there is a paucity of literature providing information on the best diagnostic and management strategies for such patients.

We present a case of a successful vaginal delivery at term in a patient with multiple cardiac risk factors with a positive exercise stress echocardiogram at 16 weeks of pregnancy. This case is presented to discuss the potential management options and demonstrate one strategy that was successful.

\section{Case Report}

A 39-year-old female with a history of type I diabetes mellitus of 32 years duration complicated by neuropathy, hypertension, and hyperlipidemia presented to her endocrinologist 13 weeks pregnant complaining of right leg paresthesias. She denied any leg swelling or erythema, chest pain, shortness of breath, orthopnea, palpitations, dizziness, lightheadedness or syncope. Her activity was limited by leg cramps after walking two blocks or climbing two flights of stairs. She reported no prior history of coronary artery disease, peripheral vascular disease, or stroke. Her diabetes was well controlled with a hemoglobin A1C of 6.4 and hypertension was controlled on atenolol $50 \mathrm{mg}$ once a day with blood pressure of 110/60 mm Hg. Her lipid profile consisted of a LDL of $120 \mathrm{mg} / \mathrm{dl}$, HDL $59 \mathrm{mg} / \mathrm{dl}$, and triglycerides $270 \mathrm{mg} / \mathrm{dl}$ while taking simvastatin. However, this was discontinued during prenancy. She had a 15-pack-year smoking history but quit 2 years ago and had no family history of premature coronary artery disease.

Physical examination was unremarkable and her electrocardiogram was normal. A stress electrocardiogram was ordered by her endocrinologist which revealed $2 \mathrm{~mm}$ of down-sloping ST depression in leads II, III, aVF, and V3-V6 at 3 minutes post exercise which resolved 9 minutes post exercise. She exercised 8.5 min- utes to stage 7 of Cornell protocol stopping secondary to fatigue and achieving max Mets 8.9 and PRP 245.

She was referred to cardiology at 16 weeks pregnancy at which time the impression was the she had multiple risk factors for coronary artery disease in the absence of any symptoms with a positive stress ECG. Her cardiologist reviewed her history, physical examination, and the stress ECG and felt that the abnormal stress ECG could indicate either ischemia or a false positivity due to left ventricular hypertrophy from her longstanding hypertension. An exercise stress echocardiogram was performed and the patient stopped at 10 minutes/stage 5 of Cornell protocol secondary to fatigue and achieved 7.0 Mets and PRP 216. Her baseline echocardiogram was normal but her stress echocardiographic images revealed hypokinesis of the anterior wall, distal $2 / 3$ of lateral wall and apex consistent with large territory of inducible ischemia.

At this point, there was a debate among her physicians regarding the safety of continuing pregnancy. The cardiologist felt that as the patient was asymptomatic, she could be safely managed through her pregnancy with aggressive medical treatment and close follow-up, while her obstetrician felt that the risk of continuing pregnancy to the mother and fetus was high and recommended abortion. As no further guidance was provided for either strategy from the review of literature at this point, these options were discussed with the patient and she elected for the strategy of medical treatment because of her strong desire to continue her pregnancy. Although catheterization was a consideration, it was decided that it would be best performed if the mother developed any untoward adverse event while continuing her pregnancy.

The patient remained asymptomatic throughout pregnancy on a regimen of methyldopa $250 \mathrm{mg}$ po tid, atenolol $75 \mathrm{mg}$ po qd, insulin, isosorbide mononitrate 30 $\mathrm{mg}$ po qd, aspirin $81 \mathrm{mg}$ po qd, and colesevelam (a new bile-acid binding resin-trade name Welchol) 3 tabs po qd.

The patient underwent a forceps assisted vaginal delivery after 8 hours of labor with epidural anesthesia giving birth to a completely healthy baby. As a result of the intravenous fluids received in the peripartum period, she had a net 3 liters of positive fluid balance over the next 24 hours. She consequently developed acute shortness of breath the next day after her delivery. A chest X-ray at that point revealed pulmonary edema and an ECG showed approximately $1 \mathrm{~mm}$ of ST depres- 
sion in leads V3-V6. Her troponin peaked at 5.7 (normal $<2.0$ ) and a surface echocardiogram showed an ejection fraction of $50 \%$ with an area of apical and anterior hypokinesis.

She was treated aggressively with diuretics, nitrates, and an angiotensin converting enzyme inhibitor and responded rapidly to this therapy and was ambulating without difficulty the following day with normal oxygenation. Given the fact that she had significant vaginal bleeding, she was discharged home on metoprolol, lisinopril, ASA, simvastatin, and insulin to be followed closely by her cardiologist with further work-up of her coronary artery disease at a later time when she had recuperated from her pregnancy and her vaginal bleeding had stopped.

She remained stable after discharge on medical management and underwent cardiac catheterization 4 weeks postpartum. Left ventriculography showed an ejection fraction of $60 \%$ without wall motion abnormalities or mitral regurgitaton. Coronary angiography revealed a left dominant system with a $70 \%$ mid left main stenosis, $100 \%$ mid LAD, $70 \%$ ostial first diagonal, $60-69 \%$ ostial circumflex, and a $70 \%$ mid circumflex lesion. The right coronary artery was non-dominant and free of disease.

2 weeks later she underwent a four-vessel coronary artery bypass graft surgery with a left internal mammary artery to the left anterior descending coronary artery, and saphenous vein grafts to the second diagonal, obtuse marginal and left posterolateral branch.

\section{Discussion \\ Potential Strategy for Managing Asymptomatic Coronary Artery Disease Based on our Patient}

Pregnant patients at high risk for coronary artery disease should be screened non-invasively. We report that a strategy of aggressive medical therapy and close followup of a patient with even severe asymptomatic coronary artery disease can help carry her safely through pregnancy without any increased risk to mother or fetus. Although it is difficult to make generalized recommendations for all such patients based on one case, it suggests that medical management is a reasonable option with cardiac catheterization reserved for patients that become unstable during follow-up. Importantly, given the significant morbidity and mortality with myocardial infarction during pregnancy, it is prudent to evaluate for coronary artery disease especially in those at high risk. Symptoms are often absent or often dismissed as being part of a normal pregnancy. Such detection of the presence of coronary artery disease in a pregnant patient will allow for aggressive modification of risk and result in better outcomes as seen in our patient.

We cannot speculate how this patient and her baby would have done if an invasive strategy was adopted at the beginning, when first seen by her cardiologist. Surprisingly, we found scant data on pregnant patients with asymptomatic coronary artery disease on review of the literature, providing no guidelines on management of such patients and calling for a common sense approach that is tailored for individual patients.

\section{Coronary Artery Disease in Pregnancy}

There have been two large reviews of the literature regarding myocardial infarction during pregnancy $[1,2]$. Hankins et al [1] report 68 cases of myocardial infarction during pregnancy with an overall maternal mortality of $37 \%$ and a fetal mortality of $34 \%$. The maternal mortality was highest in the third trimester $(45 \%)$ and when delivery occurred within 14 days of initial myocardial infarction (47\%). However, only $13 \%$ of the women were known to have coronary artery disease prior to pregnancy. The review by Roth et al [2], which studied 125 patients and also included the postpartum period, reports an overall maternal mortality of $21 \%$ and infant mortality of $12 \%$. Maternal mortality was highest in the peripartum (35\%) and postpartum (30\%) period. Only $7 \%$ of these patients had previously documented ischemic heart disease. Maternal mortality is particularly high among diabetic (IDDM) pregnancies complicated by myocardial infarction with death occurring in half of these patients [4]. Although this mortality data concern for maternal safety in the case presented, it should be remembered that our patient was asymptomatic from her coronary artery disease and her peripartum risk was modified by aggressive medical management because her disease was detected early.

\section{Diagnosis of Ischemic Heart Disease}

Recommendations for stress testing during pregnancy should be in accordance with the American College of Cardiology and the American Heart Association guidelines for stress testing in patients with coronary artery disease [5]. However, it should be noted that the safety of stress testing during pregnancy has not been fully established. Animal studies have shown decreased uterine blood flow during heavy exercise without adverse fetal effects. A study of eight women at 35-38 weeks preg- 
nancy showed a $30 \%$ increase in uterine artery impedance with exercise to $85 \%$ maximum heart rate. There was no fetal bradycardia [6]. However, another study showed 3/18 fetal bradycardic events with maximum exercise without adverse fetal outcome [7]. These findings have led to recommendations that exercise stress testing during pregnancy should be done with fetal monitoring with a goal of exercise to $70 \%$ maximum heart rate [8]. Echocardiography is safe during pregnancy and should be the imaging modality of choice for pregnant patients undergoing stress testing. There are no reports of pharmacologic stress testing during pregnancy. Dobutamine is listed as pregnancy category B (Table 1) [9], but there are no reports of its use during pregnancy. Animal studies have shown no teratogenic effects. Adenosine has been used in pregnancy for termination of supraventricular tachycardias without alteration of fetal heart rate or other serious fetal or maternal toxicity [10-13]. Dipyridamole has also been used during pregnancy in conjunction with aspirin for patients with prosthetic heart valves. In one report, four normal pregnancies resulted in neonates of normal weight without congenital abnormalities [14]. Another report of eight patients included six live births (one with incurving fifth fingers bilaterally), one 13-week abortion, and a second abortion at 22 weeks after 9 weeks of warfarin therapy [15].

Radiation exposure is an important issue with nuclear stress testing and cardiac catheterization. Radiation exposure during organ formation (10-50 days) may cause teratogenesis and generally should be avoided if

Table 1. United States Food and Drug Administration (FDA) pregnancy risk category definition.

Tabelle 1. Definition der Schwangerschaftrisikokategorien nach United States Food and Drug Administration (FDA).

A Controlled studies in women fail to demonstrate a risk to the fetus in the first trimester, and the possibility of fetal harm appears remote.

B Animal studies do not indicate a risk to the fetus and there are no controlled human studies, or animal studies do show an adverse effect on the fetus but well-controlled studies in pregnant women have failed to demonstrate a risk to the fetus.

C Studies have shown that the drug exerts animal teratogenic or embryocidal effects, but there are no controlled studies in women, or no studies are available in either animals or women.

D Positive evidence of human fetal risk exists, but benefits in certain situations (eg, life-threatening situations or serious diseases for which safer drugs cannot be used or are ineffective) may make use of the drug acceptable despite its risks.

$X$ Studies in animals or humans have demonstrated fetal abnormalities or there is evidence of fetal risk based on human experience, or both, and the risk clearly outweighs any possible benefit. possible. Beyond this period, there are still risks of intrauterine growth retardation and central nervous system abnormalities along with potential increased risk of malignancy. High level fluoroscopy or cine-radiography could deliver 5-10 rad/minute or radiation. Exposure to the uterus and embryo should be minimized with the use of lead apron. It is believed the uterus/embryo absorb less than $5 \%$ of the radiation. Exposure to less than $10 \mathrm{rad}$ is considered low risk, but termination of pregnancy is recommended for exposure over 15 rad. Cardiac nuclear imaging with thallium or sestamibi is associated with fetal radiation of 1-2 rad [8]. Nevertheless, it should be avoided if there are safer alternatives. Routine cardiac catheterization also poses little risk, but percutaneous intervention prolongs the cine time leading to significant radiation exposure.

\section{Medical Therapy}

Aspirin is considered safe at doses less than $150 \mathrm{mg}$ per day in the second and third trimesters, although the safety of its use in the first trimester is a source of an ongoing debate [16]. Prior reports have raised concern for maternal and fetal hemorrhage [17], congenital abnormalities (abnormal septation of the truncus arteriosus), and more importantly, premature closure of the ductus arteriosus at higher doses [18]. However, a metaanalysis of eleven studies did not show an increased risk of placental abruption or perinatal mortality at doses less than $200 \mathrm{mg}$ per day [19]. Although aspirin is secreted in breast milk, it has not been shown to cause any adverse side effects in infants.

Beta blockers: There have been no reports of teratogenesis with use of beta blockers. Concern for intrauterine growth retardation exists although there are no definitive studies establishing such an association. Pruyn et al [20] studied twelve pregnancies with long-term propranolol therapy and noted that only one infant was above the 50th percentile in either weight or head circumference. Additionally, five of the twelve infants were at the 10th percentile or less for head circumference. However, prospective studies of 94 pregnancies demonstrated only four infants with intrauterine growth retardation [21]. Several case reports exist with neonatal bradycardia, hypoglycemia, apnea at birth, and hyperbilirubinemia associated with propranolol use, although there have been no permanent sequelae. Larger observations do not statistically correlate these events with beta blockers. It has also been suggested that beta- 1 agents are preferred as non-selective beta 
blockers that may facilitate uterine contractions [2]. Beta blockers are also secreted in breast milk and can cause bradycardia in an infant requiring careful monitoring of their heart rate in nursing mothers.

Angiotensin Converting Enzyme (ACE) Inhibitors: Second and third trimester use is contraindicated and has been associated with serious neonatal adverse effects including renal failure, oligohydramnios, neonatal anuria, intrauterine growth retardation, premature labor, bony malformations, limb contracture, persistent patent ductus arteriosus, pulmonary hypoplasia, respiratory distress syndrome, and fetal wasting. Limb and craniofacial deformities result from oligohydramnios rather than teratogenicity of these agents. The cause-effect relationship is further confounded by the fact that women being treated with ACE inhibitors are typically those with high-risk pregnancies [22]. It has been suggested that the toxicity is not seen if use is limited to the first trimester [23]. Skull bone hypoplasia that has been most commonly reported with first trimester use is presumably from oligohydramnios and hypotension [24]. Nevertheless, women planning pregnancy should switch to other antihypertensive or vasodilating agents when on an ACE inhibitor for either hypertension or left ventricular dysfunction. ACE inhibitors are not secreted in breast milk and as such can be safely administered to nursing mothers.

Lipid Lowering Agents: Statins are considered teratogenic and should be avoided during pregnancy. A report of 134 pregnancies with inadvertent exposure to lovastatin or simvastatin resulted in normal outcomes in $85 \%$, congenital anomalies $4.0 \%$, spontaneous abortions $8.0 \%$, fetal deaths/stillbirths $1.0 \%$, and miscellaneous adverse outcomes in 2.0\% [25]. Another report of 169 women exposed to simvastatin led to 66 normal births, 40 requested induced abortions, twelve spontaneous abortions, four premature newborns, three newborns with malformations, and two fetal deaths [26]. The authors of these studies report these outcomes to be comparable to outcomes in the general population, but use of statins remains contraindicated in pregnancy. Niacin and gemfibrozil are both listed as category C. Niacin is generally not recommended for pregnancy, although there are no reports of adverse effects in pregnancy. Gemfibrozil has been safely used in a pregnant patient with lipoatrophic diabetes mellitus, although data about its use among pregnant patients in general are limited [27]. Bile acid sequestrants are category B (see Table 1) [9] and considered safe.
Antiplatelet Agents: Limited data exist on the safety of newer antiplatelet agents during pregnancy. Ticlopidine has been used safely following PTCA/stenting at 25 weeks pregnancy in one patient without IIb/IIIa inhibitors [28] and at 38 weeks in another with abciximab [29]. There have been no reports of the use of clopidogrel with or without IIb/IIIa inhibitors, although both are listed as category B for pregnancy (see Table 1) [9].

Anticoagulation: Warfarin has long been known to be teratogenic and should not be used during pregnancy, especially between the 6th and 12th weeks of gestation. One third of 418 pregnancies in which coumadin was used resulted in fetal abnormalities. Adverse effects include hemorrhagic complications, embryopathy (greatest between 6th and 12th weeks), and central nervous system abnormalities [30]. Heparin does not cross the placenta and can be used safely. Ginsberg et al [31] reported a study of 98 pregnancies with heparin therapy and showed no differences in terms of prematurity, stillbirth, abortions, deaths, or congenital abnormalities from normal population. Heparin should be discontinued with the onset of labor. Low molecular weight heparin does not cross the placenta and is probably a reasonable alternative to unfractionated heparin but dosing information is not known and because of its longer half life may require reversing of its effect during precipitous or spontaneous delivery to minimize maternal blood loss [16].

Other Agents: Nitrates and diuretics have been used safely in pregnancy. However, careful monitoring for maternal hypotension is warranted to avoid uteroplacental insufficiency and fetal distress. Digoxin is considered safe, both during pregnancy and in the postpartum period. It does cross the placenta and has been used to treat maternal and fetal arrhythmias. Nifedipine is the calcium channel blocker of choice and has been used for hypertension. Short acting nifedipine as a sole agent is best avoided for treatment of myocardial ischemia.

\section{Revascularization Options}

Percutaneous Interventions: Three cases of percutaneous transluminal coronary angioplasty without and three cases with stent implantation have been reported following myocardial infarction during pregnancy [28, 29, 32-35]. There were no reported maternal or fetal deaths in these patients. None of these cases were performed with the use of glycoprotein IIb/IIIa inhibitors and clopidogrel, the current standard of care for patients undergoing percutaneous interventions. In one 
patient, abciximab was utilized in combination with ticlopidine [29]. Further, there are no reports of percutaneous interventions in pregnant patients with stable coronary artery disease.

Coronary Artery Bypass Grafting (CABG): The largest case series reported 133 cases of open heart surgery using cardiopulmonary bypass during pregnancy with four maternal deaths $(3 \%)$ and 25 fetal deaths $(19 \%)$ [36]. Only four of these cases involved CABG with no maternal or fetal deaths, while the rest included surgeries for valvular or congenital disease [37-39]. Fetal deaths occurred mostly with aortic and mitral valve replacements and septal defect closures. Close fetal heart rate monitoring is necessary as fetal bradycardia usually corrects with increased pump flow rate and temperature. The cardioplegic solution can cause decreased uterine blood flow as it results in peripheral vasodilatation.

\section{Minimizing the Stress of Delivery}

Epidural anesthesia is recommended as it reduces pain in labor, decreases preload and afterload, and decreases cardiac stress. The mode of delivery should be primarily determined by obstetrical reasons, rather than cardiac condition. Among myocardial infarction during 66 pregnancies, Hankins et al [1] reported a 14\% maternal mortality with vaginal delivery versus $23 \%$ with cesarean section. Thus, if obstetrically indicated, vaginal delivery should be attempted. The use of vacuum or forceps to assist delivery when possible may help avoid prolonged labor reducing the stress on the heart. A left lateral decubitus position of the mother during labor may help optimize hemodynamics by displacing the uterus and increasing the venous return and cardiac output. Use of oxygen, analgesics, nitrates, and beta blockers as indicated to reduce myocardial oxygen demand are also recommended. Hematocrit should be maintained at all times above $30 \mathrm{mg} / \mathrm{dl}$. Finally, the use of intravenous hydration should be closely monitored to avoid positive fluid balance, that like in our patient, may result in acute decompensation from increased pre-load and oxygen demand.

\section{Conclusion}

Our case suggests that even patients with moderate to high risk coronary lesions who are asymptomatic can be managed safely through pregnancy and labor with aggressive medical management and close monitoring. Further, our review of literature suggests a need for a prospective registry of such patients to provide more in- sight into this issue as the current trend toward childbearing later in life continues and increases the prevalence of pregnant patients with coronary artery disease in the community at large.

\section{References}

1. Hankins GD, Wendel GD Jr, Leveno KJ, Stoneham J. Myocardial infarction during pregnancy: A review. Obstet Gynecol 1985:65: 139-46.

2. Roth A, Elkayam U. Acute myocardial infarction associated with pregnancy. Ann Intern Med 1996:125:751-62.

3. Shalev Y, Ben-Hur H, Hagay Z, Blickstein I, Epstein M, Ayzenberg O, et al. Successful delivery following myocardial ischemia during the second trimester of pregnancy. Clin Cardiol 1993:16:754-6.

4. Gordon MC, Landon MB, Boyle J, Stewart KS, Gabbe SG. Coronary artery disease in insulin-dependent diabetes mellitus of pregnancy (Class $\mathrm{H}$ ): A review of the literature. Obstet Gynecol Surv 1996:51:7:437-44.

5. Gibbons RJ, et al. ACC/AHA Guidelines for Exercise Testing: Executive Summary. Circulation 1997;96:345-54.

6. Erkkola R, Pirhonen JP, Kivijarvi AK. Flow Velocity Waveforms in Uterine and Umbilical Arteries During Submaximal Bicycle Exercise in Normal Pregnancy. Obstet Gynecol 1992;79:611-5.

7. Pipers L, Wladimiroff JW, McGhie J. Effect of Short-Term Maternal Exercise on Maternal and Fetal Cardiovascular Dynamics. Br J Obstet Gynaecol 1984;91:1081-6.

8. Elkayam U. Pregnancy and Cardiovascular Disease. In: Braunwald. Heart Disease: A Textbook of Cardiovascular Medicine, 6 th edn, 2001:2171-9o.

9. Anonymous: Pregnancy categories for prescription drugs. FDA Drug Bull 1982;12:24-5.

10. Mason BA, Ricci-Goodman J, Koos BJ. Adenosine in the Treatment of Maternal Paroxysmal Supraventricular Tachycardia. Obstet Gynecol 1992;80:478-80.

11. Podolsky SM, Varon J. Adenosine Use During Pregnancy. Ann Emerg Med 1991;20:1027-8.

12. Leffler S, Johnson DR. Adenosine Use in Pregnancy: Lack of Effect on Fetal Heart Rate. Am J Emerg Med 1992;10:548-9.

13. Hagley MT, Cole PL. Adenosine Use in Pregnant Women with Supraventricular Tachycardia. Ann Pharmacother 1994;28: 1241-2.

14. Biale $\mathrm{Y}$, Cantor A, Lawenthal $\mathrm{H}$, et al. The Course of Pregnancy in Patients with Artificial Valves Treated with Dipyridamole. Int J Gynaecol Obstet 1980;18:128-32.

15. Chen WWC, Chan CS, Lee PK, et al. Prenancy in Patients with Prosthetic Heart Valves: An Experience with 45 Pregnancies. O J Med 1982;51:358-65.

16. Ginsberg JS, Hirsch J. Use of Antithrombotic Agents During Pregnancy. Chest 1998;114:524S-30S.

17. Stuart MJ, Gross SJ, Elrad H, Graeber JE. Effects of AcetylsalicylicAcid Ingestion on Maternal and Neontatal Hemostasis. N Engl J Med 1982;307:909-12.

18. Zierler S, Rothman KJ. Congenital Heart Disease in Relation to Maternal Use of Bendectin and Other Drugs in Early Pregnancy. N Engl J Med 1985;313:347-52.

19. Hauth JC, Goldenberg RL, Parker CR, Cutter GR, Cliver SP. LowDose Aspirin: Lack of Association with an Increase in Abruptio Placentae of Perinatal Mortality. Obstet Gynecol 1995;85:6: 1055-8

20. Pruyn SC, Phelan JP, Buchanan. Long-Term Propranolol Therapy in Pregnancy: Maternal and Fetal Outcomes. Am J Obstet Gynecol 1979;135:485-9. 
21. Rubin PC. Beta-Blockers in Pregnancy. N Engl J Med 1981;305: $1323-6$.

22. Shotan A, Widerhorn J, Hurst A, Elkayam U. Risk of AngiotensinConverting Enzyme Inhibition During Pregnancy: Experimental and Clinical Evidence, Potential Mechanisms, and Recommendations for Use. Am J Med 1994;96:451-6.

23. Lip G, Beevers M, Auckett A, Beevers G. Angiotensin-ConvertingEnzyme Inhibitors in Early Pregnancy. Lancet 1997;350:1446-7.

24. Burrows RF, Burrows EA. Assessing the Teratogenic Potential of Angiotensin-Converting Enzyyme Inhibitors in Pregnancy. Aust NZ J Obstet Gynaecol 1998;38:306-11.

25. Manson JM, Freyssinges C, Ducrocq MB, Stephenson WP. Postmarketing Surveillance of Lovastatin and Simvastatin Exposure During Pregnancy. Reproduct Toxicol 1996;10:439-46.

26. Freyssinges $C$, Ducrocq MB. Simvastatin and Pregnancy. Therapie 1996;51:537-42.

27. Morse AN, Whitaker MG. Successful Pregnancy in a Women with Lipoatrophic Diabetes Mellitus. J Reproduct Med 2000;45:10: $850-2$.

28. Craig S, Ilton M. Treatment of Acute Myocardial Infarction in Pregnancy with Coronary Artery Balloon Angioplasty and Stenting. Aust NZ J Obstet Gynaecol 1999;39:194-6.

29. Sebastian C, Scherlag, Kugelmass A, Schechter E. Primary Stent Implantation for Acute Myocardial Infarction During Pregnancy: Use of Abciximab, Ticlopidine, and Aspirin. Cathet Cardiovasc Diagn 1998;45:275-9.

30. Hall J, Pauli RM, Wilson KM. Maternal and Fetal Sequelae of Anticoagulation. Am J Med 1980;68:122-40.

31. Ginsberg JS, Hirsh J, Brill-Edwards P, Burrows R. Heparin Therapy During Pregnancy. Arch Intern Med 1989;149:2233-6.

32. Ascarelli, MH, Grider AR, Hsu HW. Acute Myocardial Infarction During Pregnancy Managed With Immediate Percutaneous Transluminal Coronary Angioplasty. Obstet Gynecol 1996;88:4: $655-7$.

33. Eickman FM. Acute Coronary Artery Angioplasty During Pregnancy. Cathet Cardiovasc Diagn 1996;38:369-72.
34. Cowan NC, Belder MA, Rothman MT. Coronary Angioplasty in Pregnancy. Br Heart J 1988;59:588-92.

35. Sanchez-Ramos L, Chami Y, Bass TA, DelValle GO, Adair CD. Myocardial Infarction During Pregnancy: Management with Transluminal Coronary Angioplasty and Metallic Intracoronary Stents. Am J Obstet Gynecol 171:5:1392-3.

36. Parry AJ, Westaby S. Cardiopulmonary Bypass During Pregnancy. Ann Thorac Surg 1996;61:1865-9.

37. Garry D, Leikin E, Fleisher A, Tejani N. Acute Myocardial Infarction in Pregnancy With Subsequent Medical and Surgical Management. Obstet Gynecol 1996;87:5:802-4.

38. Silberman S, Fink D, Berko RS, Mendzelevski B, Bitran D. Coronary Artery Bypass Surgery During Pregnancy. Eur J Cardiothorac Surg 1996;10:925-6.

39. Majdan J, Walinsky P, Cowchock SF, Wapner RJ, Plzak L. Coronary Artery Bypass Surgery During Pregnancy. Am J Cardiol 1983;52: $1145-6$.

\section{Correspondence Address}

Rajendra H. Mehta, MD, MS

Clinical Assistant Professor,

Department of Internal Medicine

Division of Cardiology,

University of Michigan

2215 Fuller Road, 111A $7 \mathrm{E}$

Ann Arbor, MI 48105

USA

Phone (+1/734) -761 7157, Fax -214 0691

e-mail: rmehta@umich.edu 